\title{
PERBEDAAN MODEL PROBEM BASED LEARNING DAN DISCOVERY LEARNING TERHADAP HASIL BELAJAR MATEMATIKA
}

\author{
Dewi Rahmawati ${ }^{1}$, Henny Dewi K. ${ }^{2}$, Sri Giarti ${ }^{3}$ \\ 1,2,3 Jurusan Pendidikan Guru Sekolah Dasar, FKIP \\ Universitas Kristen Satya Wacana \\ Salatiga, Indonesia \\ Email:292014137@student.uksw.edu1, dewi@staff.uksw.edu², \\ sgiarty@gmail.com
}

\begin{abstract}
Abstrak
Penelitian ini bertujuan untuk mengetahui perbedaan yang signifikan hasil belajar Matematika antara siswa yang menggunakan model pembelajaran Problem Based Learning dengan Discovery Learning pada siswa kelas 4 SD Gugus Kanigoro Kecamatan Tingkir dan Gugus Imam Bonjol Kota Salatiga Tahun Pelajaran 2017/2018.Jenis penelitian ini adalah penelitian eksperimen semu. Desain penelitian ini yaitu Nonequivalent Control Group Design.Populasi penelitian ini adalah seluruh siswa kelas 4 SD Gugus Kanigoro sejumlah 125 siswadan Gugus Imam Bonjol yang berjumlah 117 siswa. Sampel penelitian ini yaitu kelas 4 SDN Sidorejo Kidul 02 yang berjumlah 28 orang dan siswa kelas 4 SDN Sidorejo Lor 04 yang berjumlah 40 orang. Metode pengumpulan data dilakukan dengan metode tes yaitu dengan instrumen tes objektif (pilihan ganda). Data yang diperoleh dianalisis dengan menggunakan teknik analisis statistik deskriptif dan teknik analisis statistik inferensial yaitu uji-t. Hal ini dapat dilihat dari skor rata-rata siswa yang menggunakan model pembelajaran Discovery learning yaitu 70,93 dan skor rata-rata siswa yang menggunakan model pembelajaran Problem Based learning yaitu 73,87. . Berdasarkan hasil uji T-Test dapat dilihat bahwa nilai asyimp. Sig (2-tailed) sebesar 0.016 lebih kecil dari nilai $\alpha=0.05$ sehingga terima $H_{0}$ dan tolak $H_{1}$. Hasil uji tersebut memberikan kesimpulan terdapat perbedaan hasil belajar matematika yang signifikan pada siswa kelas 4 SD Gugus Kanigoro dan Gugus Imam Bonjol dalam pembelajaran menggunakan model pembelajaran Problem based Learning dan Discovery Learning.
\end{abstract}

Kata Kunci : Pembelajaran Matematika, Model Problem based Learning, Model Discovery Learning

\begin{abstract}
This study aims to determine the significant differences in the learning outcomes of Mathematics between students using Problem Based Learning model with Discovery Learning in grade 4 students Elementary School Gugus Kanigoro Tingkir District and Imam Bonjol Group Salatiga City Lesson Year 2017 / 2018. This type of research is experimental research false. The design of this research is Nonequivalent Control Group Design.Population of this research is all 4th graders of elementary school of Gugus Kanigoro number 125 student and Imam Bonjol Group which amounted to 117 students. The sample of this research is class 4 SDN Sidorejo Kidul 02 which amounted to 28 people and 4th grade students of SDN Sidorejo Lor 04 which amounted to 40 people. Methods of data collection is done by the test method that is with the objective test instrument (multiple choice). The data obtained were analyzed using descriptive statistical analysis technique and inferential statistical analysis technique ie $t$-test. This can be seen from the average score of students using the learning model Discovery learning is 70.93 and the average score of students using the learning model Problem Based learning is 73.87. . Based on the T-Test test results can be seen that the value of asyimp. Sig (2-tailed) of 0.016 is smaller than $\alpha=0.05$ so accept $H O$ and reject H1. The result of the test gives conclusion that there are significant differences in mathematics learning outcomes in grade 4 students of SD Kanigoro Cluster and Gugus Imam Bonjol in learning using Problem Based Learning and Discovery Learning model.
\end{abstract}

Keywords: Mathematics Learning, Problem Based Learning Model, Model Discovery Learning 


\section{Pendahuluan}

Kurikulum merupakan rencana mengenai isi, tujuan, dan bahan ajar yang disusun sebagai pedoman dalam pembelajaran untuk mencapai tujuan UU Sistem Pendidikan Nasional No. 20 Tahun 2003). Kurikulum 2013 merupakan implikasi penyempurnaan kurikulum 2006 atau Kurikulum Tingkat Satuan Pendidikan (KTSP).

Berdasarkan Permendikbud No 24 Tahun 2016 Pasal 1 ayat 3 menyatakan bahwa pelaksanaan pembelajaran pada Sekolah Dasar/Madrasah Ibtidaiyah (SD/MI) dilakukan dengan pendekatan pembelajaran tematik-terpadu, kecuali untuk mata pelajaran Matematika dan Pendidikan Jasmani Olahraga dan Kesehatan (PJOK) sebagai mata pelajaran yang berdiri sendiri untuk kelas IV, V, dan VI.

Seperti dijelaskan di atas bahwa kurikulum 2013 Matematika sebagai mata pelajaran yang berdiri sendiri yang memiliki definisi yaitu ilmu yang mempelajari tentang bilangan, bentuk-bentuk (geometri) yang dapat diekspresikan dan dioperasikan melalui simbolsimbolnya dimana memerlukan keterampilan berpikir khususnya dalam berlogika atau mengamati pola dan berpikir rasional (Wahyudi dan Siswanti Mia Christy, 2015: 26).

Berpijak pada pengertian matematika sebagai ilmu berpikir dan berargumentasi tentang bilangan dan simbol dengan pola objek yang bertumpu pada kesepakatan serta memberikan kontribusi dalam menyelesaikan masalah sehari-hari. Maka pembelajaran matematika didefinisikan sebagai pembelajaran yang seharusnya mengubah citra dari pembelajaran yang mekanistis menjadi humanistik yang menyenangkan (Muchlis Effie Efrida, 2012:136).

Berdasarkan pengertian pembelajaran matematika, maka pembelajaran matematika ini lebih mengarahkan pada pembelajaran mekanistis menjadi humanistik yang menyenangkan. serta pemahaman konsep-konsep yang mengembangkan kemampuan berpikir dan menyelesaikan masalah matematika dan ilmu pengetahuan lainnya. Agar dapat mengembangkan kemampuan berpikir siswa dalam menyelesaikan masalah matematika maka guru memilih model pembelajaran yang berbasis pemecahan masalah.

Permendikbud Nomor 65 Tahun 2013 tentang Standar Proses menjelaskan bahwa model pembelajaran yang sesuai dengan pembelajaran Kurikulum 2013 yaitu: (1) pembelajaran Inkuiri, (2) pembelajaran Discovery, (3) pembelajaran berbasis projek, dan (4) pembelajaran berbasis permasalahan. Ditambah lagi menurut Permendikbud Th. 2016 No. 22 Untuk memperkuat pendekatan ilmiah (scientific), tematik terpadu (tematik antar mata pelajaran), dan tematik (dalam suatu mata pelajaran) perlu diterapkan pembelajaran berbasis penyingkapan/penelitian (discovery/inquiry learning). Sedangkan untuk mendorong kemampuan peserta didik untuk menghasilkan karya kontekstual, baik individual maupun kelompok maka sangat disarankan menggunakan pendekatan pembelajaran yang menghasilkan karya berbasis pemecahan masalah (project based learning).

Dari berbagai jenis model pembelajaran tersebut, maka model pembelajaran Probem Based Learning (PBL) dan Discovery Learning merupakan model yang sesuai digunakan dalam pembelajaran matematika.

Lebih lanjut, keampuan model PBL ini didukung oleh penelitian yang terdahulu. Hanafi Maarif \& Wahyudi (2015) dalam penelitianannya yang berjudul Eksperimentasi Problem Based Learning Dan CIRC Dalam Menyelesaikan Soal Cerita Matematika Siswa Kelas 5 SD. Penelitian lainnya yang telah di lakukan terdahulu dari model Discovery Learning. Wahyudi \& Mia Christy Siswanti (2015) dengan judul Pengaruh Pendekatan Saintifik Melalui Model Discovery Learning Dengan Permainan Terhadap Hasil Belajar Matematika Siswa Kelas 5 SD. Serta penelitian yang telah dilakukan oleh Puspita Indah Rahayu, Undang Rosidin, Abdurrahman. (2015). Perbandingan Hasil Belajar Siswa Antara Pembelajaran Menggunakan PBL Dan Discovery Learning.

Banyak keraguan tentang tentang model pembelajaran Problem Based Learning dan Discovery Learning dalam meningkatkan hasil belajar. Untuk membuktikan keraguan tentang model pembelajaran Problem Based Learning dan Discovery Learning, maka akan 
dilakukan penelitian untuk melihat apakah terdapat perbedaan antara model Problem Based Learning dan Discovery Learning. Oleh karena itu dilakukan penelitian tentang perbedaan Problem Based Learning dan Discovery Learning terhadap hasil belajar siswa kelas IV SD Gugus Kanigoro dan Imam Bonjol Salatiga Semester II Tahun Pelajaran 2017/2018.

\section{Metode}

Penelitian ini menggunakan jenis penelitian eksperimen semu atau eksperimen kuasi. Pada eksperimen kuasi ini rumusan masalah harus mengandung hubungan kausal atau sebab akibat antarvariabel yang sudah ditemukan pada saat merumuskan latar belakang. Adapun tujuan dari penelitian ini untuk menguji teori yang sudah ada. Pemberian treatment pada kelas eksperimen diharapkan mampu memberikan hasil yang lebih baik daripada kelas kontrol (Deni Darmawan, 2013: 51-52).

Penelitian ini menggunakan desain Nonequivalent Control Group Design. Terdapat dua kelompok eksperimen, yaitu kelompok eksperimen 1 dan kelompok eksperimen 2 yang dipilih tidak secara random, tetapi matching only (Kusumawati, H., \& Mawardi, M. ,2016: 256). Pemilihan kelompok eksperimen dilakukan secara matching only lebih memungkinkan untuk dilakukan dibanding pemilihan secara random; karena dalam merandom subjek penelitian dibutuhkan izin dari setiap kepala sekolah agar beberapa siswa yang ditunjuk dapat menjadi subjek penelitian. Kedua kelompok tersebut (kelompok eksperimen 1 dan kelompok eksperimen 2) diberikan pretest dan posttest untuk mengetahui adanya perbedaan yang signifikan antara kelompok eksperimen 1 dan eksperimen 2 (Yuniarta, F., 2014:116).

Sampel penelitian ini menggunakan siswa kelas 4 SD Sidorejo Kidul 02 yang berjumlah 28 siswa sebagai kelompok eksperimen 1. Siswa kelas 4 SD Negeri Sidorejo Lor 07 sejumlah 40 siswa sebagai kelompok eksperimen 2. Teknik pengumpulan data pada penelitian ini dilakukan dengan menggunakan observasi dan tes. Instrumen yang digunakan untuk mengumpulkan data dalam penelitian ini terdiri dari lembar observasi aktivitas guru dan aktivitas siswa dalam menerapkan model pembelajaran PBL dan Discovery dan lembar soal pretest dan posttest yang berjenis pilihan ganda. Berdasarkan hasil uji validitas yang telah dilakukan diperoleh data ada 40 item soal yang memiliki koefisien korelasi skor butir dengan skor total masuk dalam kategori valid $(\geq 0,30)$.

Analisis data yang digunakan dalam penelitian ini adalah dengan menggunakan analisis satu jalur karena untuk mengetahui perbedaan model $P B L$ dan Discovery Learning. Model analisis statistik yang digunakan untuk menguji hipotesis tersebut adalah independent samplet-test yang merupakan suatu teknik statistik yang berfungsi untuk menguji signifikansi perbedaan rerata antara pasangan kelompok atau perbedaan rerata pasangan amatan ulang. Proses pengolahan data dalam penelitian ini dilakukan dengan bantuan program komputer Statistical Package for Social Science (SPSS) 22 for Windows.

Hipotesis yang akan diuji dalam penelitian eksperimen ini adalah: Ho: $\mu 1=\mu 2$ Tidak terdapat perbedaan hasil belajar matematika yang signifikan pada siswa kelas 4 SD Gugus Kaanigoro dan Imam Bonjol dalam pembelajaran menggunakan model pembelajaran $P B L$ dan Discovery Learning. Ha: $\mu 1 \neq \mu 2$ Terdapat perbedaan hasil belajar matematika yang signifikan pada siswa kelas 4 SD Gugus Kangoro dan Imam Bonjol dalam pembelajaran menggunakan model pembelajaran PBL dan Discovery Learning.

\section{Hasil dan Pembahasan}

Penelitian ini dilakukan di kelas 4 SDN Sidorejo Kidul 02 sebagai kelas eksperimen I dan kelas 4 SD Sidorejo Lor 07 sebagai kelas eksperimen II. Perbandingan hasil pengukuran kelompok eksperimen 1 dan kelompok eksperimen 2 berdasarkan nilai pretest dan posttest akan dipaparkan pada deskripsi komparasi ini. Deskripsi tersebut disajikan dalam bentuk tabel dan grafik sebagai berikut. 
Tabel 1. Tabel Komparasi Hasil Pengukuran Kelompok Eksperimen 1

\begin{tabular}{llll}
\hline \multirow{2}{*}{ Tahap Pengukuran } & \multicolumn{2}{l}{ Rerata skor (mean) kelompok } & \multirow{2}{*}{ Keterangan Selisih } \\
& Ekspermen 1 & Esperimen 2 & \\
\hline Pretes & 64,82 & 67,13 & 2,31 \\
Postes & 70,93 & 73,87 & 2,94 \\
\hline
\end{tabular}

Berdasarkan Tabel 1 di atas, dapat diketahui adanya perbedaan skor rata-rata tahap pengukuran pretest dan posttest kelompok eksperimen 1 dan kelompok eksperimen 2 . Perbedaan skor rata-rata tersebut ditunjukkan oleh adanya selisih skor rata-rata antara kelompok eksperimen 1 dan kelompok eksperimen 2. Pada tahap pengukuran pretest terdapat perbedaan skor rata-rata yang ditunjukkan oleh adanya selisih skor antara kelompok eksperimen 1 dan kelompok eksperimen 2 sebesar 2,31. Pada tahap pengukuran pretest, rata-rata kolompok eksperimen 1 lebih unggul dibandingkan skor rata-rata kelompok eksperimen 2. Sedangkan pada tahap pengukuran posttest terdapat perbedaan skor ratarata kelompok eksperimen 1 dan kelompok eksperimen 2 sebesar 7. Pada tahap pengukuran posttest, skor rata-rata kelompok eksperimen 1 lebih unggul dibandingkan skor rata-rata kelompok eksperimen 2.

Hasil uji perbedaan rerata hasil belajar kelompok eksperimen 1 dan eksperimen 2 serta teknik analisis data menggunakan uji T Test setelah dilakukan uji prasyarat dan dilanjutkan dengan uji hipotesis. Uji prasyarat yang dilakukan yaitu uji normalitas data dan uji homogenitas variansi data. Uji normalitas digunakan untuk mengetahui distribusi kenormalan data, uji homogenitas digunakan untuk mengetahui tingkat kesetaraan data. Pengujian normalitas dan homogenitas data dilakukan dengan bantuan SPSS 22 for Windows.

Uji normalitas data dilakukan untuk mengetahui data berasal dari distribusi normal atau tidak. Pengujian normalitas data dilakukan dengan bantuan uji Kolmogorov-Smirnov, dengan dasar pengambilan keputusan; jika nilai signifikansi/probabilitas $<0,05$, maka data berdistribusi tidak normal. Apabila nilai signifikansi/probabilitas $>0,05$, maka data berdistribusi normal.

Tabel 2. Hasil Uji Normalitas Skor Pretest-Posttest Kelompok Eksperimen 1 dan Kelompok Eksperimen 2

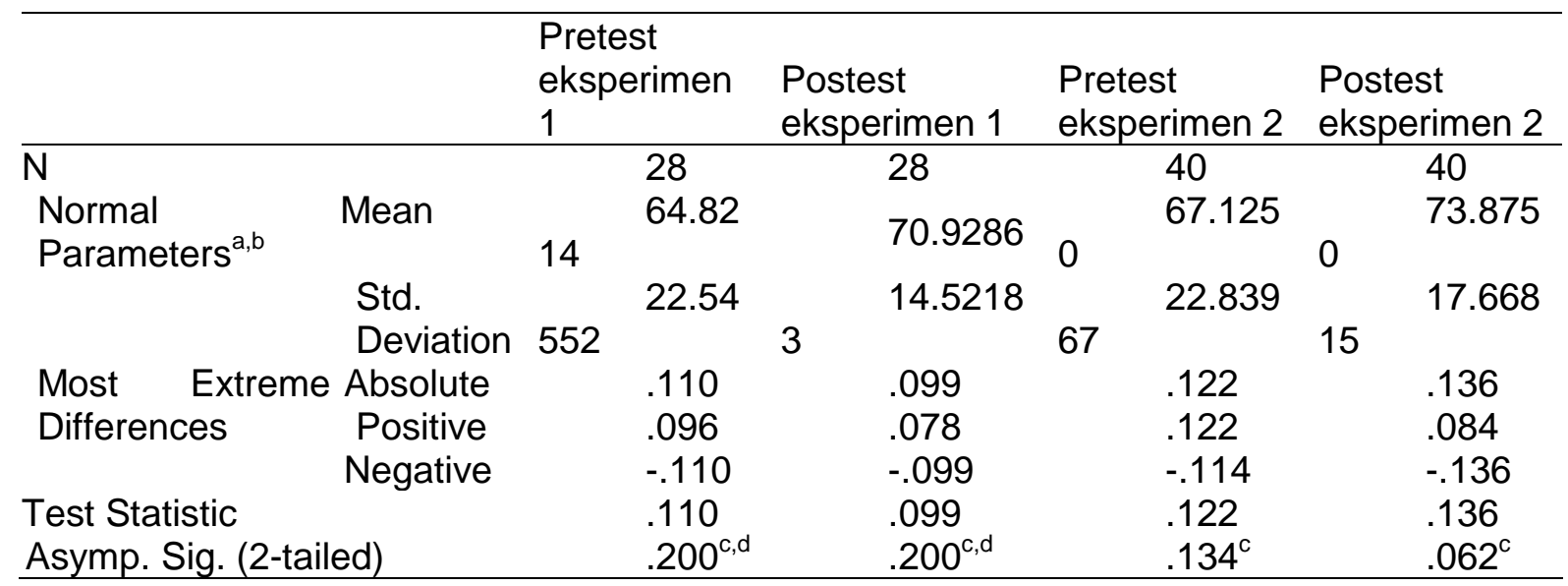

Berdasarkan tabel $4.6 \mathrm{di}$ atas dapat dilihat bahwa nilai Asymp. Sig. (2-tailed) uji Kolmogorov-Smirnov $Z$ hasil pretest-posttest kelompok eksperimen 1 adalah 0,200 dan 0,200 . Sedangkan hasil pretest-posttest kelompok eksperimen 2 adalah 0,134 dan 0,062. Bila dirumuskan sebuah hipotesis $\mathrm{H}_{0}$ adalah sebuah sampel yang berasal dari populasi berdistribusi normal dan $\mathrm{H}_{\mathrm{a}}$ adalah sampel yang tidak berasal dari populasi berdistribusi 
normal, maka dapat diputuskan jika probabilitas < nilai a $(0,05) \mathrm{H}_{0}$ ditolak, jika sebaliknya maka $\mathrm{H}_{0}$ diterima. Oleh karena nilai signifikansi/probabilitas Asymp. Sig. (2-tailed) data-data tersebut berturut-turut 0,200; 0,200; 0,134 dan 0,062 > 0,05 maka $\mathrm{H}_{0}$ diterima, artinya dapat disimpulkan bahwa persebaran data hasil pretest-posttest kelompok eksperimen 1 dan kelompok eksperimen 2 tersebut berasal dari populasi yang berdistribusi normal.Setelah uji normalitas terpenuhi, selanjutnya dilakukan uji homogenitas untuk mengetahui varian kedua kelompok homogen atau tidak. Apabila nilai signifikansi/probabilitas $<0,05$, maka data dikatakan tidak homogen. Apabila nilai signifikansi/probabilitas $>0,05$, maka data dikatakan homogen. Pengujian homogenitas dilakukan dengan menggunakan bantuan SPSS 22 for windows. Berikut hasil dari uji homogenitas data kelompok eksperimen 1 dan kelompok eksperimen 2.

Tabel 3. Hasil Uji HomogenitasSkorPretest-Posttest Kelompok Eksperimen 1 dan Kelompok Eksperimen 2

Test of Homogeneity of Variances

\begin{tabular}{|c|c|c|c|c|}
\hline \multicolumn{3}{|c|}{ Levene Statisticdf1 } & \multirow{2}{*}{$\mathrm{df} 2$} & \multirow{2}{*}{$\begin{array}{r}\text { Sig. } \\
, 731\end{array}$} \\
\hline PostTest & ,119 & 48 & & \\
\hline PreTest &, 513 & 78 & & ,337 \\
\hline
\end{tabular}

Berdasarkan tabel 4.7 di atas diketahui bahwa hasil Test of Homogeneity of Variances signifikansi/probabilitas nilai pretest menunjukkan angka 0,337 . Bila dirumuskan sebuah hipotesis $\mathrm{H}_{0}$ adalah variansi data pada tiap kelompok sama (homogen) dan $\mathrm{H}_{a}$ adalah variansi data pada tiap kelompok tidak sama (tidak homogen), maka dapat diputuskan jika probabilitas < nilai a $(0,05) \mathrm{H}_{0}$ ditolak, jika sebaliknya maka $\mathrm{H}_{0}$ diterima. Oleh karena nilai signifikansi/probabilitas data pretes dan postes kedua kelompok adalah sebesar 0,337 dan 0,731 > 0,05 maka $\mathrm{H}_{0}$ diterima. Artinya dapat dikatakan bahwa skor pretest kelompok eksperimen 1 dan kelompok eksperimen 2 adalah homogen. Skorsignifikansi/probabilitas posttest kelompok eksperimen 1 dan kelompok eksperimen 2 adalah 0,731, dengan demikian dapat dikatakan bahwa nilai posttest kelompok eksperimen 1 dan kelompok eksperimen 2 adalah homogen. Melihat skor signifikansi/probabilitas pretest-posttest kelompok eksperimen 1 dan kelompok eksperimen 2, dapat disimpulkan bahwa data skor pretest-posttest kelompok eksperimen 1 dan kelompok eksperimen 2 memiliki varian data yang homogen atau sama.

Tabel 4. Hasil Uji T Test Posttest Kelompok Eksperimen 1 dan Kelompok Eksperimen 2

\begin{tabular}{|c|c|c|c|c|c|c|c|c|c|c|}
\hline \multirow{4}{*}{$\begin{array}{l}\text { Hasil } \\
\text { Belajar } \\
\text { Maematik } \\
\text { a }\end{array}$} & \multirow{3}{*}{$\begin{array}{l}\text { Equal } \\
\text { variance }\end{array}$} & \multicolumn{2}{|c|}{$\begin{array}{l}\text { Levene's } \\
\text { Test for } \\
\text { Equality } \\
\text { of } \\
\text { Variances }\end{array}$} & \multicolumn{4}{|c|}{ t-test for Equality of Means } & \multirow{3}{*}{$\begin{array}{l}\text { Std. } \\
\text { Error } \\
\text { Differenc } \\
\text { e }\end{array}$} & \multirow{2}{*}{\multicolumn{2}{|c|}{$\begin{array}{l}95 \% \text { Confidence } \\
\text { Interval of the } \\
\text { Difference }\end{array}$}} \\
\hline & & & & & & $\begin{array}{l}\text { Sig. } \\
(2- \\
\text { tailed }\end{array}$ & $\begin{array}{l}\text { Mean } \\
\text { Differenc }\end{array}$ & & & \\
\hline & & $\mathrm{F}$ & Sig. & $\mathrm{t}$ & df & ) & e & & Lower & Upper \\
\hline & $\begin{array}{l}\text { variance } \\
\text { s } \\
\text { assume } \\
\text { d }\end{array}$ & $\begin{array}{l}2.09 \\
0\end{array}$ & $\begin{array}{l}.15 \\
3\end{array}$ & $\begin{array}{l}.72 \\
7\end{array}$ & 66 & .016 & 2.94643 & 4.05428 & $\begin{array}{l}11.0410 \\
7\end{array}$ & $\begin{array}{l}5.1482 \\
1\end{array}$ \\
\hline
\end{tabular}




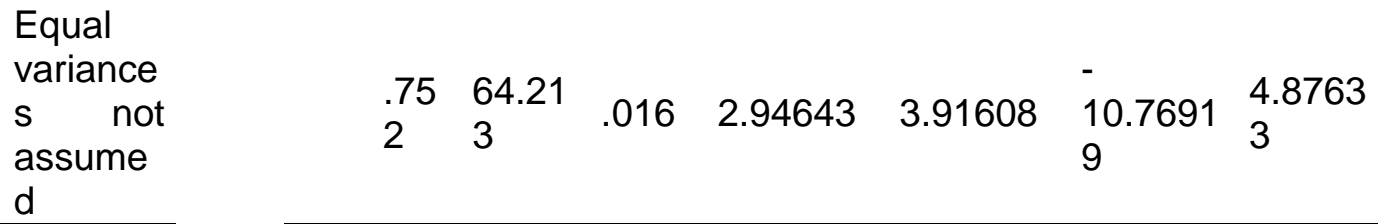

Equal

Berdasarkan hasil uji Independent Sample T Test dapat dilihat bahwa nilai asyimp. Sig (2-tailed) sebesar 0.016 lebih kecil dari nilai $\alpha=0.05$ sehingga terima $H_{0}$ dan tolak $H_{1}$. Hasil uji tersebut memberikan kesimpulan bahwa terdapat perbedaan rata-rata antara kedua kelas eksperimen. Selain untuk mengetahui perbedaan hasil belajar, penelitian ini juga untuk mengetahui lebih tinggi mana hasil belajar antara model Problem based Learning dan Discovery Learning.

Penelitian ini bertujuan untuk mengetahui perbedaan hasil belajar yang signifikan dalam penerapan model Problem based Learning dan Discovery Learning pada mata pelajaran matematika kelas 4 SD Gugus Kangoro dan Imam Bonjol. Hasil uji hipotesis menggunakan teknik $T$ Test seperti telah dilakukan terhadap nilai pretest dan posttest kelompok eksperimen 1 dan kelompok eksperimen 2 diperoleh hasil signifikansi/probabilitas $0,016<0,05$, oleh karena probabilitas lebih kecil dari nilai Alpha, maka $\mathrm{H}_{0}$ ditolak dan $\mathrm{Ha}$ diterima. Artinya terdapat perbedaan hasil belajar matematika yang signifikan pada siswa kelas 4 SD Gugus Kangoro dan Imam Bonjol dalam pembelajaran menggunakan model Problem based Learning dan Discovery Learning.

Signifikansi perlakukan dimana terdapat perbedaan hasil belajar matematika yang signifikan pada siswa kelas 4 SD Gugus Kangoro dan Imam Bonjol dalam pembelajaran menggunakan model pembelajaran Problem based Learning dan Discovery Learning didukung oleh rerata dari dua sampel dimana rerata hasil belajar pada penerapan model pembelajaran Problem based Learning sebesar 70,93, sedangkan rerata hasil belajar pada penerapan model Discovery Learning sebesar 73,87. Maknanya adalah bahwa perbedaan rerata hasil belajar dan signifikansi perlakuan membuktikan bahwa model pembelajaran Discovery Learning memberikan dampak berbeda dan lebih tinggi daripada model pembelajaran Problem based Learning.

Hasil penelitian ini sejalan dengan penelitian yang dilakukan oleh Wahyudi \& Mia Christy Siswanti (2015) Pengaruh Pendekatan Saintifik Melalui Model Discovery Learning Dengan Permainan Terhadap Hasil Belajar Matematika Siswa Kelas 5 SD. Berdasarkan hasil penelitian diperoleh bahwa ada pengaruh penerapan pendekatan saintifik melalui model discovery learning dengan permainan terhadap hasil belajar matematika siswa kelas 5 semester II SD Kristen 03 Eben Haezer Salatiga Tahun Pelajaran 2014/2015. Rata-rata kelas eksperimen 80,84 sedangkan kelas kontrol 71,75. Hal ini juga didukung dari nilai $t$ hitung $>\mathrm{t}$ tabel, yaitu $(4,905>2.018)$ dan signifikan $0,000<0,05$ yang menunjukkan bahwa $\mathrm{HO}$ ditolak $\mathrm{H} 1$ diterima.

\section{Simpulan Dan Saran}

Berdasarkan hasil analisis data yang telah dipaparkan, maka dapat disimpulkan bahwa terdapat perbedaan hasil belajar matematika yang signifikan pada siswa kelas 4 SD Gugus Kanigoro dan Gugus Imam Bonjol dalam pembelajaran menggunakan model pembelajaran Problem based Learning dan Discovery Learning. Hal ini didasarkan pada hasil uji hipotesis yang menunjukkan bahwa $\mathrm{H}_{0}$ ditolak dan $\mathrm{H}_{\mathrm{a}}$ diterima. Berdasarkan uji $T$ Test yang telah dilakukan terhadap nilai posttest kelompok eksperimen 1 dan kelompok eksperimen 2 diperoleh hasil signifikansi/probabilitas $0,016<0,05$, maka $\mathrm{H}_{0}$ ditolak dan $\mathrm{H}_{\mathrm{a}}$ diterima. Artinya terdapat perbedaan hasil belajar matematika yang signifikan pada siswa kelas 4 SD Gugus Kanigoro dan Gugus Imam Bonjol dalam pembelajaran menggunakan model pembelajaran Problem based Learning dan Discovery Learning.

Signifikansi perlakukan dimana terdapat perbedaan hasil belajar matematika yang signifikan pada siswa kelas 4 SD Gugus Kanigoro dan Gugus Imam Bonjol dalam 
pembelajaran menggunakan model pembelajaran Problem based Learning dan Discovery Learning didukung oleh rerata dari dua sampel dimana rerata hasil belajar pada penerapan model pembelajaran Problem based Learning sebesar 70,93, sedangkan rerata hasil belajar pada penerapan model pembelajaran sebesar 73,87. Maknanya adalah bahwa perbedaan rerata hasil belajar dan signifikansi perlakuan membuktikan bahwa model pembelajaran Problem based Learning memberikan dampak berbeda dan lebih tinggi daripada model pembelajaran Discovery Learning.

Saran untuk guru itu guru dapat menerapkan model pembelajaran pada mata pelajaran matematika kelas 4 SD.

Bagi siswa untuk selalu antusias mengikuti kegiatan pembelajaran dan meningkatkan hasil belajarnya.

Bagi Kepala Sekolah, dapat memperkenalkan Model pembelajaran kepada guru kelas ataupun kepada Kepala Sekolah yang lain di SD Gugus Kanigoro dan Gugus Imam Bonjol, supaya menjadi referensi guru dalam mengembangkan suasana pembelajaran yang bermakna.

Bagi Peneliti Selanjutnya, hasil penelitian ini dapat digunakan sebagai referensi bagi peneliti berikutnya, dengan memperhatikan kekurangan/keterbatasan yang terdapat pada penelitian ini agar menjadi perbaikan untuk penelitian berikutnya.

\section{Daftar Rujukan}

Darmawan, D. (2013). Metode penelitian kuantitatif.

Dewi, K. A. P., Gading, I. K., \& Sudana, D. N. (2016). Pengaruh Model Pembelajaran Problem Based Learning (PBL) Terhadap Hasil Belajar IPA Siswa Kelas IV SD. MIMBAR PGSD Undiksha, 4(1).

Giarti, S. (2015, November). Peningkatan Keterampilan Proses Pemecahan Masalah dan Hasil Belajar Matematika Menggunakan Model PBL Terintegrasi Penilaian Autentik Pada Siswa Kelas VI SDN 2 Bengle, Wonosegoro. In Prosiding Seminar Pendidikan Ekonomi dan Bisnis (Vol. 1, No. 1).

Hanafiah, N. (2010). Konsep Strategi Pembelajaran. Bandung: Refika Aditama.

Haryati, N. (2015). Hubungan Minat Belajar Dengan Prestasi Belajar Matematika Siswa Kelas V Sd Se-Gugus Wonokerto Turi Sleman Tahun Ajaran 2014/2015 (Doctoral dissertation, PGSD).

Ibnu, T. (2014). Mendesain Model Pembelajaran Inovatif, Progesif dan Kontekstual: Konsep, Landasan, dan Implementasinya pada Kurikulum 2013 (Kurikulum Tematik Terintregatif). Jakarta: Prenadamedia Group.

Kristiana, I., \& Kristiana, M. O. (2014). Penerapan Model Problem Based Learning Untuk Meningkatkan Motivasi Dan Hasil Belajar Pada Mata Pelajaran IPS Siswa Kelas IV SD Negeri 3 Tempuran Lampung Tengah Tahun Pelajaran 2012/2013.

Kusumawati, H., \& Mawardi, M. (2016). Perbedaan Penerapan Model Pembelajaran Kooperatif Tipe NHT dan STAD Ditinjau dari Hasil Belajar Siswa. Scholaria: Jurnal Pendidikan dan Kebudayaan, 6(3), 251-263.

Maarif, H., \& Wahyudi, W. (2015). Eksperimentasi Problem Based Learning dan CIRC dalam Menyelesaikan Soal Cerita Matematika Siswa Kelas 5 SD. Scholaria: Jurnal Pendidikan dan Kebudayaan, 5(2), 97-115. 
Muchlis, E. E. (2012). Pengaruh pendekatan pendidikan matematika realistik indonesia (PMRI) terhadap perkembangan kemampuan pemecahan masalah siswa kelas II SD Kartika 1.10 Padang. EXACTA, 10(2), 136-139.

Muhamad, N. (2017). Pengaruh Metode Discovery Learning untuk Meningkatkan Representasi Matematis dan Percaya Diri Siswa. Jurnal Pendidikan UNIGA, 10(1), 9-22.

Nomor, P. (21). tahun 2016 tentang Standar Isi. Jakarta: Depdikbud.

Nomor, P. (22). tahun 2016 tentang Standar Proses. Jakarta: Depdikbud.

Nomor, P. (24). tahun 2016 tentang Kompetensi Inti dan Kompetensi Dasar. Jakarta: Depdikbud.

Nomor, P. (65). tahun 2013 tentang Standar Proses. Jakarta: Depdikbud.

Rahayu, P. I., Rosidin, U., \& Abdurrahman, A. (2015). Perbandingan Hasil Belajar Siswa antara Pembelajaran Menggunakan PBL dan Discovery Learning. Jurnal Pembelajaran Fisika, 3(5).

Rusmono. (2014). Strategi Pembelajaran dengan Problem Based Learning untuk Meningkatkan Profesionalitas Guru. Bogor: Ghalia Indonesia.

Supraptinah, U., Budiyono, B., \& Subanti, S. (2015). Eksperimentasi Model Pembelajaran Discovery Learning, Problem Based Learning, Dan Think-Talk-Write Dengan Pendekatan Saintifik Terhadap Kemampuan Pemecahan Masalah Matematika Ditinjau Dari Kemandirian Belajar Siswa. Jurnal Pembelajaran Matematika, 3(10).

Undang-undang Republik Indonesia No. 20 Tahun 2003 tentang Sitem Pendidikan Nasional. 2003. Jakarta: Presiden Republik Indonesia.

Wahyudi, W., \& Siswanti, M. C. (2015). Pengaruh Pendekatan Saintifik Melalui Model Discovery Learning dengan Permainan Terhadap Hasil Belajar Matematika Siswa Kelas 5 SD. Scholaria: Jurnal Pendidikan dan Kebudayaan, 5(3), 23

Wahyuni, D. (2017). Penerapan Discovery Learning Untuk Meningkatkan Kemampuan Membaca Pemahaman Siswa Kelas VB SD Negeri 004 Bukit Datuk Kota Dumai Tahun Pelajaran 2015/2016. e-Jurnal Mitra Pendidikan, 1(3), 79-90.

Yuniarta, F. (2014). Penerapan Pembelajaran Inkuiri Terbimbing Untuk Meningkatkan Keterampilan Generik Sains Siswa SMP. Jurnal Pengajaran MIPA, 19(1), 111-116. 